Research Paper

\title{
Medulloblastoma and Brucellosis - Molecular Evidence of Brucella sp in Association with Central Nervous System Cancer
}

\author{
Binxue Zhang ${ }^{1,3}$, Mina Izadjoo ${ }^{1,3}$, Iren Horkayne-Szakaly², Alan Morrison², Douglas J. Wear ${ }^{1 凶}$ \\ 1. Division of Wound and Translational Research, Department of Environmental and Infectious Disease Sciences, Armed \\ Forces Institute of Pathology, Washington, DC 20306-6000, USA; \\ 2. Department of Neuropathology, Armed Forces Institute of Pathology, Washington, DC 20306-6000, USA; \\ 3. American Registry of Pathology, Washington DC, USA
}

Corresponding author: Douglas J. Wear, MD, Department of Environmental and Infectious Disease Sciences, Armed Forces Institute of Pathology, 6825 16th St., N.W., Bldg. 54, Room 1029, Washington, DC 20306-6000, USA. Phone 202-782-1849; Fax: 202-782-9160; E-mail; douglas.j.wear@us.army.mil

(C) Ivyspring International Publisher. This is an open-access article distributed under the terms of the Creative Commons License (http://creativecommons.org/ licenses/by-nc-nd/3.0/). Reproduction is permitted for personal, noncommercial use, provided that the article is in whole, unmodified, and properly cited.

Received: 2011.02.17;

\begin{abstract}
Neurobrucellosis has been reported to cause lesions in a number of different locations in the central nervous system. Histologically or radiologically, these lesions were consistent with an infection. In response to parents who believed their child's brain tumor, histologically typical of medulloblastoma, was in reality neurobrucellosis, formalin-fixed paraffin-embedded tumor tissue from the medulloblastoma was sectioned, DNA extracted, and tested by polymerase chain reaction (PCR). Specific primer/probe sets, designed in our laboratory to target Brucella species, B. melitensis, B. abortus and B. suis, and designated OMP3I, B-m, B-a and B-s, respectively, were used in TaqMan real-time PCR to amplify those gene targets in two separate blocks of the child's tumor. Sections from two blocks were positive only for Brucella species. Although the patient grew up in a European country known to harbor brucella in foods, such as unpasturized milk and cheese, the patient was seronegative for $B$. mellitensis, $B$. suis, and $B$. abortus. In an effort to test whether a relationship existed between the presence of brucella and medulloblastoma, 20 medulloblastomas were retrieved from the tissue repository of the AFIP. The above four primer/probe sets were again used to amplify brucella DNA. Five of 20 tumors (25\%) contained Brucella species DNA by the OMP3I primer/probe set. None of the 20 medulloblastomas had specific sequences for B. mellitensis, B. suis, or B. abortus. Is chronic brucellosis similar to other infectious agents such as helicobacter that is associated with tumor formation?
\end{abstract}

Key words: brucellosis; Brucella sp; medulloblastoma; glioblastoma; Formalin-Fixed Paraffin-Embedded (FFPE); milk; dairy.

\section{Introduction}

Medulloblastoma, a primitive neuro-ectodermal tumor (PNET) arising in the posterior fossa, is one of the most common malignant tumor of the central nervous system (CNS) in children. Overall survival for children with non-disseminated and non-anaplastic medulloblastoma can approach $80 \%{ }^{1}$
Radiologic and histopathologic features include hyperattenuation on unenhanced computed tomographic scans that reflects the high nuclear-cytoplasmic ratio seen at histological analysis. ${ }^{2}$ Medulloblastoma can also occur in late middle age with identical histopathologic findings to those found 
in childhood. Studies of chromosomal abnormalities, genetic syndromes, and individual genes have contributed to the understanding of medullblastoma biology. ${ }^{3}$

An infectious association with medulloblastoma was proposed in 2002. Del Valle et al demonstrated the presence of the human polyoma virus (JCV) T antigen (Tag), and agnoprotein DNA in $65 \%$ and $69 \%$ of 20 and 16 medulloblastoma FFPE specimens, respectively. ${ }^{4}$ In an accompanying editorial "Polyomavirus and Medulloblastoma: A Smoking Gun or Guilt By Association?" Howard A. Fine ${ }^{5}$ cautioned "only through well-controlled epidemiological case-control studies evaluating large numbers of both normal and tumor-associated brains for the presence of JCV, will we have a chance of determining the relative contribution of the virus toward tumor promotion." Over the years PCR findings have not confirmed a viral association with medullolastoma. ${ }^{6-9}$

Brucellosis is caused by an intracellular gram-negative coccobacillus and produces lesions in multiple organs including the brain. Exposure to Brucella species occurs through drinking or eating unpasteurized milk products, meat, or contact with infected animals. CNS brucellosis is rare. In a study of 19 patients in 1987, 8 patients had meningoencephalitis, 6 had proximal polyradiculoneuritis, and 5 had diffuse CNS involvement (including one with cerebellar involvement). ${ }^{10}$ In a study of 301 brucellosis patients in 1992, 18 had neurobrucellosis, two patients exhibited cerebellar dysfunction. ${ }^{11}$

In 2009 a 14 year-old girl presented with double vision. On MRI examination a $5 \times 3 \mathrm{~cm}$ mass was centered in the fourth ventricle. Resection of the mass revealed a small blue cell tumor forming scattered Homer-Wright rosettes, characteristic of classic medulloblastoma. Immunohistochemical staining excluded lymphoma and metastases. Initial IgM for brucella was $0.78(<0.50 \mathrm{neg})$ and IgG was negative. Repeat IgM was negative. In response to the parents who believed the mass was actually neurobrucellosis, the AFIP performed PCR testing for Brucella sp DNA in the tumor tissue. Surprisingly DNA extracted from two formalin-fixed, paraffin-embedded (FFPE) tissue blocks contained a 62 base pair (bp) sequence of DNA found only in the outer membrane protein gene (OMP31) of Brucella species. Specific primers/probes for B. melitensis, B. abortus, and B. suis did not produce a DNA product from the two tumor blocks.

In order to assess if brucella may have any association with medulloblastoma, we retrieved FFPE blocks from brains of patients who died of medulloblastoma as well as blocks of brains from patients who died with other malignancies in the CNS, and brains of patients without evidence of CNS tumors. This study showed an unexpected presence of Brucella sp in FFPE CNS tissues from patients who died from malignancy in the brain.

\section{Materials and Methods \\ Clinical Samples}

A total of 52 FFPE autopsy samples of brain tissues were collected from the pathology archives of the Armed Forces Institute of Pathology. Thirty-one had evidence of malignancy, 21 were without evidence of malignancy. Of the 31, 20 were diagnosed as medulloblastomas, 5 as glioblastoma, 4 as metastatic carcinoma and 2 with leukemia.

\section{DNA retrieval from FFPE sections}

Fifty-two FFPE blocks were cut with a microtome ( $5 \mu \mathrm{m}$ in thickness, 3 sections per block). All cut-sections were collected into separate DNase-free Eppendorf tubes and processed for DNA retrieval as follows: (i) de-paraffinized by treatment with $800 \mu \mathrm{l}$ of xylene (twice) followed by removing xylene with 800 $\mu \mathrm{l}$ of pure ethanol treatment (twice); (ii) tissue digestion and nucleic acids separation were carried out following a modified protocol of a QIAGEN Kit (Cat\# 51106); (iii) RNA cleaning by incubation samples at $37{ }^{\circ} \mathrm{C}$ for 30 minutes with RNase A $(100 \mathrm{mg} / \mathrm{ml}$, QIAGEN) and (iv) DNA was purified by QIAquick column (washing buffer 1 and 2, QIAGEN). The final DNA samples were eluted off the columns in $30 \mu \mathrm{l}$ of elution buffer (QIAGEN), followed by quantification with ND-1000 Spectrophotometer (NanoDrop). All DNA samples were stored at $-20^{\circ} \mathrm{C}$ for later usage. Before use the DNA concentration was adjusted below $150 \mathrm{ng} / \mu \mathrm{l}$.

\section{TaqMan PCR primers and probes}

Four sets of TaqMan primers and probes were designed for identification of Brucella at species level (set 1 - 3) or at genus level (set 4). Brucella species-specific assays for B-m, B-a and B-s targets were determined by selecting the insertion sequences (IS711 elements) ${ }^{12}$ in the genome of Brucella melitensis (Region 1209562...1209713, AE008917.1), B. abortus (701208...701381, AM040265.1), and B. suis (1618822...1618948, AE014291.4), respectively. The amplicon length in each primer set ranged from 127 to $174 \mathrm{bp}$, and each amplicon was checked in silico by BLAST alignment program. The OMP31 primer set (set 4) was developed to amplify Brucella OMP31gene target (31 KDa outer membrane protein) (Locus: BruAb1_1608; Region 1586489...1587274; AE017223). All primers were designed with Primer Express Software (v 3.0, Applied Biosciences, ABI). The 62-bp 
nucleotides in the OMP31 gene fragment was amplified with primer GGCTCGGTTGCCAATATC $(\mathrm{f})$ and GACTGCGTAAAGCCGGACTC (r). A TaqMan hydrolysis probe FAM-tgcgatcaagtcgggcgctct-TAMRA, designed by using the same software, hybridizes with the specific amplicon as shown by an in silico PCR amplification. ${ }^{13}$ The 62-bp fragment demonstrated a broad range of alignment with Brucella species. All primer oligos were ordered from Integrated DNA Technology (IDT), and TaqMan probes from ABI.

\section{Validation of TaqMan real-time PCR assays and amplification conditions}

Validation tests of each assay were carried out by testing standard Brucella DNA, extracted from culture of B. melitensis $16 \mathrm{M}$ strain. Bacterial culture was conducted in a BSL-3 laboratory at the AFIP. Standard DNA serial dilutions (10-fold) were from 200 picogram (pg) to 200 femtogram (fg) per microliter. A specificity DNA panel was prepared by collecting DNA samples from cultures of Brucella sp (Table 1), near neighbors and other bacteria (not shown).

Table I. Brucella DNA Panel Tested by TaqMan Primer / Probe Sets

\begin{tabular}{lllll}
\hline Organisms & B-m & B-a & B-s & Omp31 \\
\hline B. abortus & - & + & - & + \\
B. cetacae & - & - & - & + \\
B. maris & - & - & - & + \\
B. melitensis (16M) & + & - & - & + \\
B. melitensis(349CA) & + & - & - & + \\
B. pinnipedia & - & - & - & + \\
B. canis & - & - & - & + \\
B. ovis & - & - & - & + \\
B. suis & - & - & + & + \\
B. microti & - & - & - & + \\
\hline
\end{tabular}

The validation results demonstrated that the limitation of detection (LoD) of these real-time PCR assays is around $50 \mathrm{fg}$, equivalent to 5 Brucella genomes. The calculation was performed according to Brucella genome size (B. melitensis, $16 \mathrm{M}$ str., $2.12 \mathrm{Mb}$ ) and a real-time PCR standard amplification curve (data not included). Specificity tests confirmed no cross-species amplification among primer set 1 to 3; OMP31 primers amplified all Brucella DNAs in the DNA panel. TaqMan real-time PCR reaction was carried out in a LightCycler (Software 4.1, Roche). In PCR assay, each capillary $(20 \mu \mathrm{l})$ contained 10X buffer (with $50 \mathrm{mM} \mathrm{MgCl}$, IT), dNTPs (2 mM each, IT), TaqMan primers (300 nM each), probe $(50 \mathrm{nM})$, Taq polymerase (1 unit, Invitrogen) and $5 \mu$ l of DNA samples. Cycle conditions were as follow: Reaction capillary was incubated at $95^{\circ} \mathrm{C}$ for 2 minutes, followed by 40 cycles of two-step amplification: $95^{\circ} \mathrm{C}$ for zero seconds and $60^{\circ} \mathrm{C}$ for 20 seconds.

\section{Results}

The association of brain tumors, medulloblastoma as an example, with the presence of a Brucella species DNA has not been previously addressed. Parents of a patient with medulloblastoma however, insisted that Brucella was associated with their child's brain tumor. This prompted us to investigate the presence of Brucella sp DNA in medulloblastoma tumor tissues. These samples represent different histologic presentations, classic, anaplastic, nodular, large cell, and included samples with the more general terminology primitive neuro-ectodermal tumor (PNET).

After finding the child's medulloblastoma did contain Brucella sp DNA, we asked members of the Department of Neuropathology to retrieve brain tumors, especially medulloblastoma from the archives. In Table 2, 20 brain specimens diagnosed as medulloblastoma were tested for Brucella sp DNA. Five (25\%) patients' tissues were positive only for the outer membrane protein gene (OMP31). All were male, ages ranged from 4 to 24 , average 13.8 years. All died in the United States of America. Fifteen (75\%) patients' medulloblastoma tissues contained no OMP31 gene sequences. These 15 patient's ages ranged from 6 months to 27 years, average 12.5 years. Three patients died in Europe and 12 died in the United States. None of the 20 cases contained specific sequences related to B. melitensis, B. abortus, or B. suis.

In order to determine if Brucella sp DNA is present in the brain of patients dying of non-malignant disorders, 21 brain samples were retrieved and tested for Brucella sp specific DNA sequence (OMP31 gene fragment). One patient (4.8\%) (\#15 Table 3) who died with changes consistent with his diagnosis of spinocerebellar ataxia had Brucella sp DNA in his brain tissue. The remaining 20 had no identifiable Brucella sp DNA sequences. The male to female ratio of the 21 patients was $4: 1$, average age 53.3 years.

Brain tissues from 11 patients diagnosed with other malignancies were also examined using the OMP31 primer/probe set (Table 4). Four of 11 contained Brucella sp DNA sequences, in which three of five $(60 \%)$ of brains diagnosed as glioblastoma, 1 of 4 brains $(25 \%)$ with the histologic diagnosis of metastatic carcinoma, and neither of the two brains with a diagnosis of leukemia demonstrated Brucella sp DNA sequences. 
In summary, 10 of the $52(19 \%)$ brain tissues retrieved from the archival files of AFIP contained Brucella sp DNA (outer membrane protein -OMP31 gene fragment). Specific Brucella sp DNA was identified in $25 \%$ of the medulloblastomas, $60 \%$ of the glioblastomas, and $25 \%$ of the metastatic carcinomas.

Table 2. Evidence of Brucella sp DNA in 20 who died of medulloblastoma related tumors

\begin{tabular}{lllll}
\hline $\begin{array}{l}\text { Patient } \\
\text { (No) }\end{array}$ & PCR (+/-) & Age $(\mathrm{yrs})$ & $\mathrm{M} / \mathrm{F}$ & Diagnoses \\
\hline 1 & - & 0.5 & $\mathrm{~F}$ & PNET with astrocytic differentiation \\
2 & - & 1 & $\mathrm{~F}$ & PNET with glial differentiation \\
3 & + & 4 & $\mathrm{M}$ & Medulloblastoma \\
4 & - & 5 & $\mathrm{M}$ & Anaplastic with rare nodules \\
5 & - & 6 & $\mathrm{~F}$ & Large cell medulloblastoma \\
6 & + & 7 & $\mathrm{M}$ & Medulloblastoma \\
7 & - & 8 & $\mathrm{M}$ & PNET/medulloblastoma \\
8 & - & 8 & $\mathrm{M}$ & Nodular medulloblastoma \\
9 & - & 9 & $\mathrm{M}$ & Anaplastic medulloblastoma \\
10 & - & 9 & $\mathrm{M}$ & Medulloblastoma \\
11 & + & 12 & $\mathrm{M}$ & Classic Medulloblastoma \\
12 & - & 13 & $\mathrm{~F}$ & Medulloblastoma \\
13 & - & 14 & $\mathrm{M}$ & Anaplastic/classic medulloblastoma \\
14 & - & 18 & $\mathrm{~F}$ & PNET \\
15 & - & 21 & $\mathrm{M}$ & Classic medulloblastoma \\
16 & + & 22 & $\mathrm{M}$ & Medulloblastoma \\
17 & - & 22 & $\mathrm{M}$ & Anaplastic medulloblastoma \\
18 & + & 24 & $\mathrm{M}$ & Medulloblastoma \\
19 & - & 26 & $\mathrm{~F}$ & Anaplastic medulloblastoma \\
20 & - & 27 & $\mathrm{M}$ & Medulloblastoma \\
\hline & & & & \\
\hline
\end{tabular}

Table 3 Evidence of Brucella sp DNA in CNS of twenty-one without evidence of malignancy

\begin{tabular}{|c|c|c|c|c|}
\hline $\begin{array}{l}\text { Patient } \\
\text { (No) }\end{array}$ & $\mathrm{PCR}(+/-)$ & Age (yrs) & $\mathrm{M} / \mathrm{F}$ & Diagnoses \\
\hline 1 & - & 0.5 & F & Nonspecific changes \\
\hline 2 & - & 0.5 & M & Acute hypoxic ischemic neuronal injury \\
\hline 3 & - & 9 & M & Vascular malformation; subarachnoid hemorrhage \\
\hline 4 & - & 26 & $\mathrm{~F}$ & Minimal histological changes \\
\hline 5 & - & 26 & M & Acute hypoxic ischemic neuronal injury \\
\hline 6 & - & 37 & $\mathrm{~F}$ & Arteriolar sclerosis \\
\hline 7 & - & 49 & M & Nonspecific changes \\
\hline 8 & - & 55 & M & Arteriolar sclerosis \\
\hline 9 & - & 56 & M & Reactive change; arteriolar sclerosis \\
\hline 10 & - & 62 & M & Alzheimer disease; amyloid angiopathy \\
\hline 11 & - & 66 & M & Hepatitis, seizures \\
\hline 12 & - & 68 & $\mathrm{M}$ & Dementia with Lewy bodies \\
\hline 13 & - & 69 & M & Chronic infarction; arteriolar sclerosis \\
\hline 14 & - & 71 & M & Hemorrhagic stroke \\
\hline 15 & + & 72 & $\mathrm{~F}$ & Changes of spinocerebellar ataxia; amyloid angiopathy \\
\hline 16 & - & 74 & M & Ascites \& chronic infarctions \\
\hline 17 & - & 74 & M & Arteriolar sclerosis; atherosclerosis \\
\hline 18 & - & 77 & M & Neurodegenerative changes \\
\hline 19 & - & 86 & M & Alzheimer disease; amyloid angiopathy \\
\hline 20 & - & 88 & M & Neurodegenerative changes \\
\hline 21 & - & NA & NA & Foci consistent with demyelination; ischemic changes \\
\hline
\end{tabular}


Table 4. Evidence of Brucella sp DNA in CNS of I I who died of non-medulloblastoma malignancies

\begin{tabular}{lllll}
\hline $\begin{array}{l}\text { Patient } \\
(\text { No })\end{array}$ & PCR (+/-) & Age (yrs) & M/F & Diagnosis \\
\hline 1 & - & 3 & F & Glioblastoma \\
2 & + & 38 & F & Glioblastoma \\
3 & + & 48 & M & Metastatic small cell carcinoma \\
4 & - & 52 & F & Glioblastoma \\
5 & + & 56 & M & Glioblastoma \\
6 & + & 62 & M & Glioblastoma \\
7 & - & 66 & M & Metastatic small cell carcinoma \\
8 & - & 69 & M & Myeloid leukemia \\
9 & - & 75 & M & Metastatic poorly differentiated carcinoma \\
10 & - & 79 & M & Metastatic squamous cell carcinoma \\
11 & - & 81 & M & Subacute/Chronic lymphocytic leukemia \\
\hline
\end{tabular}

\section{Discussion}

The idea of a Brucella species or the disease brucellosis being associated with brain tumors, specifically medulloblastoma or glioblastoma must be addressed with caution. Howard A. Fine's words outlining the need for a "well-controlled epidemiological case-control study evaluating large numbers of both normal and tumor-associated brains" in the suggestion that JC virus was associated with medulloblastoma formation exactly outlines the tasks necessary to affix any role of brucellosis in patients who develop medulloblastomas or other brain tumors.

There are several problems in collecting sufficient material to conduct a full study. The first is the number of cases available with FFPE tissue blocks. We were only able to obtain material from 20 patients with medulloblastoma. The second is using the optimal size primer/probe sets. Sensitive and specific PCR primers are crucial for accurate characterization of disease biomarkers in FFPE tissue. In primer designing, if amplicon size is longer than $200 \mathrm{bp}$, PCR is often unsuccessful. ${ }^{14,15}$ We used Primer Express Software (v 3.0) for designing all TaqMan assay primers and probes. The software generates amplicons of smaller size, usually between 60 to $150 \mathrm{bp}$, that just fits the amplification of FFPE DNA fragments. As shown in Table 1, the OMP31primer set amplifies Brucella sp as opposed to near neighbors. The resulting PCR amplicon

[GGCTCGGTTGCCAATATCAATGCGATCAA GTCGGGCGCTCTGGAGTCCGGCTTTACGCAGTC] only aligned with Brucella species (100\% identity) on Blast search. The third problem is the necessity to guard against DNA contamination in the cutting, ex- traction, and real-time PCR amplification processes. The ideal study would be conducted at separate sites using identical primer/probe sets.

Is there any evidence that bacteria or bacteria-like agents can be implicated in cancer formation? One bacterial species has been shown to have an association with cancer. Gastric cancer develops in persons infected with Helicobacter pylori but not in uninfected persons. ${ }^{16}$ One bacteria-like agent $\mathrm{Myco-}$ plasma fermentans has been shown in the laboratory to induce a Mycoplasma-mediated multistage malignant transformation of cultured mouse embryo cells $\left(\mathrm{C}_{3} \mathrm{H}\right) \cdot{ }^{17}$

Positive DNA findings for Brucella species in our index patients focused our attention on studying medulloblastomas, as shown in this index patient, serological examination and cultures for brucellosis were non-contributory. This might mean that live Brucella $s p$ organisms are not present, only Brucella $s p$ DNA. In the United States, people drink pasteurized milk and milk products and eat meats from antibiotic treated animals. Is it possible that the source of the detected Brucella sp DNA was denatured DNA from diet, not from an active Brucella sp infection? More studies would be needed to further investigate any true association between Brucella $s p$ DNA positivity and CNS tumor formation.

\section{Conflict of Interest}

The authors have declared that no conflict of interest exists.

\section{References}

1. Klesse LJ, Bowers DC. Childhood medulloblastoma: current status of biology and treatment. CNS Drugs. 2010; 24:285-301. 
2. Koeller KK, Rushing EJ. From the archives of the AFIP: medulloblastoma: a comprehensive review with radiologic-pathologic correlation. Radiographics. 2003; 23:1613-1637.

3. Collins VP. Brain tumours: classification and genes. J Neurol Neurosurg Psychiatry. 2004;75(Suppl 2):ii2-ii11.

4. Del Valle L, Gordon J, Enam S, Delbue S, Croul S, Abraham S, Radhakrishnan S, Assimakopoulou M, Katsetos CD, Khalili K. Expression of human neurotropic polyomavirus JCV late gene product agnoprotein in human medulloblastoma. J Natl Cancer Inst. 2002; 94:267-273.

5. Fine HA. Polyomavirus and medulloblastoma: a smoking gun or guilt by association? J Natl Cancer Inst. 2002 Feb 20; 94 (4):240-241.

6. Kim JY, Koralnik IJ, LeFave M, Segal RA, Pfister LA, Pomeroy SL. Medulloblastomas and primitive neuroectodermal tumors rarely contain polyomavirus DNA sequences. Neuro Oncol. 2002; 4:165-170.

7. Okamoto H, Mineta $\mathrm{T}$, Ueda S, Nakahara $\mathrm{Y}$, Shiraishi $\mathrm{T}$, Tamiya T, Tabuchi K. Detection of JC virus DNA sequences in brain tumors in pediatric patients. J Neurosurg. 2005;102 (3 Suppl): 294-298.

8. Rollison DE, Utaipat U, Ryschkewitsch C, Hou J, Goldthwaite P, Daniel R, Helzlsouer KJ, Burger PC, Shah KV, Major EO. Investigation of human brain tumors for the presence of polyomavirus genome sequences by two independent laboratories. Int J Cancer. 2005;113:769-774.

9. Muñoz-Mármol AM, Mola G, Ruiz-Larroya T, Fernández-Vasalo A, Vela E, Mate JL, Ariza A. Rarity of JC virus DNA sequences and early proteins in human gliomas and medulloblastomas: the controversial role of JC virus in human neurooncogenesis. Neuropathol Appl Neurobiol. 2006; 32:131-140.

10. Shakir RA, Al-Din AS, Araj GF, Lulu AR, Mousa AR, Saadah MA. Clinical categories of neurobrucellosis. A report on 19 cases. Brain. 1987;110( Pt 1):213-223.

11. McLean DR, Russell N, Khan MY. Neurobrucellosis: clinical and therapeutic features. Clin Infect Dis. 1992;15:582-590.

12. Halling SM, Tatum FM and Bricker BJ. Sequence and characterization of an insertion sequence, IS711, from Brucella ovis. Gene. 1993; 133:123-127.

13. Bikandi J, Sanmillan R, Rementeria A, Garaizar J. Oxford Journals-Life Sciences-Bioinformatics. 2003; Vol. 20, issue 5, Pp798-799.

14. Siwoski A., et al. An efficient method for the assessment of DNA quality of archival microdissected specimens. Modern Pathology. 2002;15:889-892.

15. Van Beers EH. A multiplex PCR predictor for aCGH success of FFPE samples. British Journal of Cancer. 2006; 94:333-337.

16. Uemura N, Okamoto S, Yamamoto S, Matsumura N, Yamaguchi S, Yamakido M, Taniyama K, Sasaki N, Schlemper RJ. Helicobacter pylori infection and the development of gastric cancer. N Engl J Med. 2001; 345:784-789.

17. Tsai S, Wear DJ, Shih JW, Lo SC. Mycoplasmas and oncogenesis: persistent infection and multistage malignant transformation. Proc Natl Acad Sci USA. 1995; 92 (22):10197-10201. 